\title{
Dominique Rabaté, Pascal Quignard. Étude de l'œuvre
}

\section{Stefano Genetti}

\section{(2) OpenEdition}

\section{Journals}

\section{Edizione digitale}

URL: http://journals.openedition.org/studifrancesi/7725

DOI: ERREUR PDO dans /localdata/www-bin/Core/Core/Db/Db.class.php L.34 : SQLSTATE[HY000]

[2006] MySQL server has gone away

ISSN: 2421-5856

\section{Editore}

Rosenberg \& Sellier

\section{Edizione cartacea}

Data di pubblicazione: 1 décembre 2009

Paginazione: 670-671

ISSN: 0039-2944

\section{Notizia bibliografica digitale}

Stefano Genetti, «Dominique Rabaté, Pascal Quignard. Étude de l'œuvre», Studi Francesi [Online], 159 (LIII | III) | 2009, online dal 30 novembre 2015, consultato il 08 janvier 2021. URL: http://

journals.openedition.org/studifrancesi/7725 ; DOI: https://doi.org/ERREUR PDO dans /localdata/ www-bin/Core/Core/Db/Db.class.php L.34 : SQLSTATE[HY000] [2006] MySQL server has gone away

Questo documento è stato generato automaticamente il 8 janvier 2021.

\section{c) $\$$}

Studi Francesi è distribuita con Licenza Creative Commons Attribuzione - Non commerciale - Non opere derivate 4.0 Internazionale. 


\title{
Dominique Rabaté, Pascal Quignard. Étude de l'œuvre
}

\author{
Stefano Genetti
}

\section{NOTIZIA}

DOMINIQUe RABATÉ, Pascal Quignard. Étude de l'œuvre, Paris, Bordas, 2008 («écrivains au présent», 1), pp. 192.

1 Il fatto che quest'agile ma densa monografia, concepita come «une invitation [...] au ravissement de la lecture» (p. 10), inauguri la collana «Écrivains au présent» diretta da Dominique Viart, è indicativo del crescente interesse suscitato da una delle principali voci della letteratura contemporanea. Saggi e articoli, atti di convegno e numeri di rivista si sono accumulati negli ultimi anni e l'A. fa il punto della situazione, secondo un approccio utilmente comparabile a quello adottato, in un analogo contributo recente, da un altro specialista: JEAN-LOUIS PAUTROT, Pascal Quignard ou le fonds du monde, Amsterdam-New York, Rodopi («Collection monographique Rodopi en littérature française contemporaine», 46), 2007, pp. 197.

2 Laddove IRENA KRISTEVA (Pascal Quignard. La fascination du fragmentaire, Paris, L'Harmattan, 2008, pp. 348), pur trattando in un'ottica mitocritica e psicoanalitica di aspetti onnipresenti in Quignard quali la frammentarietà come istanza etica ed esigenza estetica, la folgorazione e il desiderio, lo scrivere e il leggere, la musica e il silenzio, si concentra soprattutto sui Petits traités, La Haine de la musique e Le Sexe et l'effroi, sia Rabaté che Pautrot affrontano questi e altri argomenti - la riflessione sul linguaggio, sulla lettera e sull'immagine, il senso del dettaglio e la passione etimologica, la solitudine, l'estasi e la malinconia, la rimozione dell'animalità umana e l'allucinazione onirica, figurativa e poetica del "perduto" - nell'ambito di una lettura complessiva di un'opera proteiforme e tuttavia coesa. Insieme altera e coinvolgente, erudita e inquietante, un'aporetica «littérature de l'impossible» (p. 44), scrive Rabaté, 
«tire son autorité [...] de ce qui la ruine» (p. 38), vale a dire da quell'assenza originaria, incessantemente evocata proprio in quanto insondabile, immemoriale, incomunicabile.

Entrambi i saggi muovono da un aperçu biografico, teso a rintracciare nell'infanzia e nella formazione dell'autore la genealogia del suo l'immaginario, verso una rassegna di tratti e motivi ricorrenti: le letture puntuali di testi emblematici si alternano a considerazioni trasversali o evolutive, dagli autoritratti per interposta persona delle fictions critiques e delle vies imaginaires al ciclo che fa di Vie secrète e dei cinque tomi di Dernier royaume un'onnicomprensiva e asistematica ricapitolazione dell'opera tutta. Sensibile all'archeologia del romanesque perseguita da Quignard, Pautrot mantiene in qualche misura la distinzione tra saggistica e narrativa, mentre Rabaté, che si sofferma ad esempio sui contes, insegue da vicino l'intrecciarsi di speculazione e invenzione che contraddistingue una scrittura a un tempo perentoria e provvisoria. Inoltre, nell'ultima parte del libro, egli fornisce una panoramica non solo sulla ricezione da parte di altri scrittori e pensatori, da Millet a Lyotard a Nancy, ma anche sui progetti che, in un dialogo costante tra le arti, vedono Quignard collaborare con cineasti, pittori, coreografi e musicisti, da Tous les matins du monde a Requiem.

4 Se Rabaté si mostra attento alla contestualizzazione letteraria, Pautrot evidenzia efficacemente come il pensiero di Quignard si collochi all'intersezione di vari saperi antropologia, psicanalisi, filosofia, linguistica - e come la resistenza alla metafisica e la demistificazione della storia come strumento conoscitivo, la critica dell'individualismo, dell'originalità e dell'amnesia culturale che ne deriva partecipino di un ampio e condiviso ripensamento della modernità. Nel delineare, da punti di vista non sempre coincidenti ma tutt'altro che incompatibili, filiazioni e affiliazioni - da Montaigne a Lévi-Strauss e da Ba-taille a Michon -, entrambi sottolineano la pertinenza della "singolarità" dell'opera di Quignard, della sua rivendicata inattualità, rispetto agli interrogativi epistemologici e creativi del nostro tempo. 